\title{
"Jeder Antrieb unseres Tuns ist in den Tiefen der Seele begründet»
}

\section{Felicitas Witte}

Dr. med., Medizinjournalistin

\author{
Alt Bundesrat Moritz Leuenberger weiss aus eigener Erfahrung, wie sehr Motivatio- \\ nen und Handlungen die menschliche Psyche beeinflussen. Auf der Jahrestagung \\ der Schweizerischen Gesellschaft für Angst und Depressionen (SGAD) in Zürich* \\ legte er dar, wie Entwicklungen in Psychiatrie und Politik dazu beitragen, gesell- \\ schaftlich geprägte Menschenbilder und Interessen zu gestalten.
}

6th Swiss Forum for Mood and Anxiety Disorders: Hirn, Herz und Darm eine unse(e)lige Liaison. Zürich, 16. April 2015.

** In den 1960er und 1970er Jahren glichen psychiatrische Kliniken in Italien oft gefängnisartigen Einrichtungen, wo Patienten mit fragwürdigen Methoden (z.B. Elektroschocks, eiskalten Bädern, Lobotomie «behandelt» wurden. Im Sinne von «Freiheit heilt hatte eine Gruppe Psych iater um Franco Basaglia begonnen, die unmenschlichen Anstalten schrittweise zu öffnen. Die offenen Betreuungsformen brachten neue Probleme, vor allem für die Angehörigen der Patienten.
Er habe einige Bedenken gehabt, sagte alt Bundesrat Moritz Leuenberger schmunzelnd, zu einer Veranstaltung zu kommen, die vom «Forum für Angst und Depression» organisiert sei. «Hiesse es Forum gegen Angst und Depression, hätte ich vielleicht schneller zugesagt.» Wäre er noch in seinem alten Amt, hätte er zudem nie eine Rede gehalten, die seine eigene Psyche thematisiere. «Zu sehr hätte ich mich vor der Häme in den Medien gefürchtet, und meine Berater hätten mir das definitiv verboten.» Die Einführungsrede sorgte immer wieder für Heiterkeit, doch der Grundtenor blieb dem Thema entsprechend ernst und stimmte nachdenklich. Einmal, erinnerte sich Leuenberger, als der Nationalratssaal umgebaut und deswegen nicht geheizt war, hatte er sich einen Mantel angezogen, woraufhin $20 \mathrm{Mi}$ nuten schrieb: «Wie krank ist Leuenberger?». «Daraufhin musste meine Kommunikationsabteilung zum Nachweis antreten, ich sei nicht krank», erzählte der alt Bundesrat. Leuenberger schlug einen Bogen von der spektakulären Öffnung der psychiatrischen Klinik Triest im Jahre $1974^{* *}$ bis zur fürsorgerischen Freiheitsentziehung. Psychiatrie und Politik hätten an dieser Entwicklung gleichermassen mitgewirkt, und sie unterlägen beide denselben gesellschaftlichen Modeströmungen. «Vielleicht muss sich eine künftige Politikergeneration für ihre untätige Toleranz auf dem Platzspitz genauso entschuldigen, wie es die jetzige für die damaligen willkürlichen Aktionen gegenüber den Kindern der Landstrasse tun muss», sagte Leuenberger. Psychiater und Politiker seien sich oft ähnlich: "Warum werfen wir Politiker uns ins Getümmel der Arena? Warum verbringen wir halbe und ganze Nächte in Parlamentssitzungen und Parteitagen? Ich habe eine ehrliche Antwort darauf: Ich will Macht ausüben, Einfluss nehmen, die Gesellschaft mitgestalten.» Aber es gehe auch um

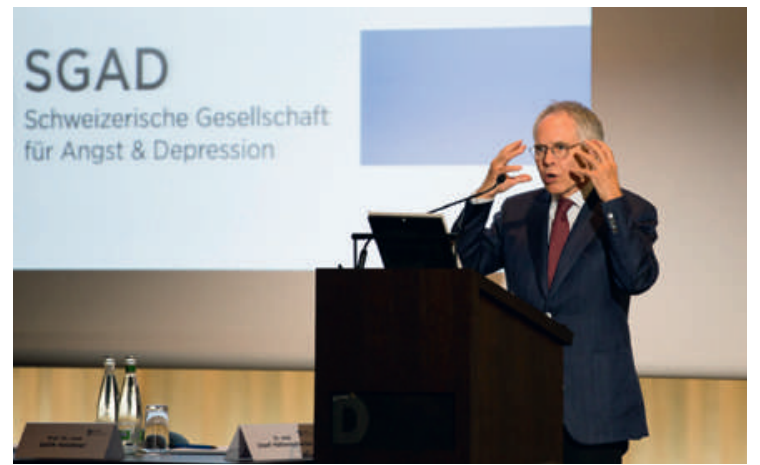

Alt-Bundesrat Moritz Leuenberger: «Entwicklungen in Psychiatrie und Politik prägen gesellschaftliche Menschenbilder und Interessen gleichermassen.»

Selbstdarstellung, darum, sich zu inszenieren, zu gefallen, sich selber zu gefallen. «Jeder Antrieb unseres Tuns, seien wir Psychiater oder Politiker, ist in den Tiefen der Seele begründet. Motivforschung über die inneren Beweggründe eines sozialen Engagements oder einer politischer Mission droht bald, in Gesinnungsinquisition zu enden. Wichtig ist das gesellschaftspolitische Resultat und nicht das egoistische Motiv.»

Im Weiteren ging Leuenberger auf die Erwartung der Wähler in ihre politischen Repräsentanten ein und schilderte, wie dies den Charakter eines Politikers verändere. Die Rücksicht auf die öffentliche Meinung nehme beängstigende Dimensionen an, wenn stets auf bösartige Interpretationen der eigenen Aussagen durch politische Gegner oder Medienvertreter geachtet werde. «Das führt zu einer diffusen Angst, die nur nach negativen Reaktionen schielt und sich diesen schliesslich unterwirft, bis dieses angstvolle Schielen das eigene Denken und Fühlen beherrscht.» Dass er heute die Einladung angenommen habe, zeige aber: «Ich habe mich ganz gut erholt.» 